\title{
Chemopreventive Activity of Turmeric Essential Oil and Possible Mechanisms of Action
}

\author{
Vijayasteltar Belsamma Liju, Kottarapat Jeena, Ramadasan Kuttan*
}

\begin{abstract}
This study aimed to evaluate the antimutagenic and anticarcinogenic activity of turmeric essential oil as well as to establish biochemical mechanisms of action. Antimutagenicity testing was accomplished using strains and known mutagens with and without microsomal activation. Anticarcinogenic activity was assessed by topical application of 7,12 - dimethylbenz[a]anthracene (DMBA) as initiator and $1 \%$ croton oil as promoter for the induction of skin papillomas in mice. Inhibition of 450 enzymes by TEO was studied using various resorufins and aminopyrene as substrate. Turmeric essential oil (TEO) showed significant antimutagenic activity $(\mathbf{p}<0.001)$ against direct acting mutagens such as sodium azide $\left(\mathrm{NaN}_{3}\right)$, 4-nitro-O-phenylenediamine (NPD) and N-methylN-nitro N'nitrosoguanine (MNNG). TEO was found to have significant antimutagenic effect (>90\%) against mutagen needing metabolic activation such as 2-acetamidoflourene (2-AAF). The study also revealed that TEO significantly inhibited $(\mathbf{p}<0.001)$ the mutagenicity induced by tobacco extract to Salmonella TA 102 strain. DMBA and croton oil induced papilloma development in mice was found to be delayed and prevented significantly by TEO application. Moreover TEO significantly $(P<0.001)$ inhibited isoforms of cytochrome p450 (CYP1A1, CYP1A2, CYP2B1/2, CYP2A, CYP2B and CYP3A) enzymes in vitro, which are involved in the activation of carcinogens. Results indicated that TEO is antimutagenic and anticarcinogenic and inhibition of enzymes (p450) involved in the activation of carcinogen is one of its mechanisms of action.
\end{abstract}

Keywords: Antimutagenicity - turmeric essential oil - dimethylbenz[a]anthracene - cytochrome p450

Asian Pac J Cancer Prev, 15 (16), 6575-6580

\section{Introduction}

Many human cancers are caused by chemical carcinogens, such as polycyclic aromatic hydrocarbons, heterocyclic amines, aromatic amines etc present in our environment. Continued exposure of these substances to human cells leads to genomic instability, including repair deficiency and accumulation of genetic alteration (Ames, 1983). Mutation is a major factor in carcinogenesis and incidence of cancer may be reduced by decreasing the rate of mutations induced by various chemical mutagens. Many carcinogens are activated through Phase I (cytochrome p450) enzymes present in endoplasmic reticulum of the liver cells. Induction of Phase II detoxification enzymes, such as glutathione S-transferase and UDP-glucuronyl transferase, is another mechanisms of protection against carcinogenesis (Piengchai et al., 2011). Modulating these enzymes may reduce cancer incidence.

Spices which are widely used as food ingredient exhibits different pharmacological properties. Essential oils from spices are volatile compounds produced as secondary metabolites. The essential oil from Curcuma longa rhizome is a complex mixture obtained by steam distillation. A total number of 12 components of the essential oil are identified by GC-MS analysis and the principal compounds include ar-turmerone (61\%), curlone (11.2\%), and cucumene (5.5\%) (Liju et al., 2011). Ar-turmerone, the major compound present in TEO has been shown to exhibit anticancer properties (Baik et al., 1993). Biological properties of TEO such as its antimicrobial, anti-inflammatory, antioxidant and antinociceptive activities have been reported (Negi et al., 1999; Liju et al., 2011). Studies have revealed that TEO has chemopreventive efficacy against submucus fibrosis in human (Hastak et al., 1997; Deepa et al., 2010). TEO also showed antiproliferative activity against both human oral epidermal carcinoma (KB) and murine leukemia (P388) cell lines (Manosroi et al., 2006). Nevertheless few studies have been carried out to evaluate its antimutagenic and anticarcinogenic activities.

This study examines whether TEO possess any antimutagenic ability against direct acting mutagens such as sodium azide $\left(\mathrm{NaN}_{3}\right)$, 4-nitro-o-phenylenediamine (NPD), MNNG as well as mutagens needing mammalian liver microsomal activation, such as 2-acetamidoflourene (2-AAF) using Salmonella strains TA 98, TA 100, TA 1535 and TA 102. Effect of TEO on tobacco induced mutagenicity was also evaluated. Moreover chemopreventive efficacy of TEO against skin papilloma development in mice induced by DMBA as initiator and croton oil as promoter is also being reported in this study. In order to determine the possible mechanism of action 
of TEO we have evaluated the inhibition of different cytochrome p450 enzymes by TEO in vitro.

\section{Materials and Methods}

\section{Turmeric essential oil}

The essential oil isolated by steam distillation from the rhizome of Curcuma longa was purchased from Kancore Ingredients Limited., Angamali, Kerala, India. TEO was dissolved in DMSO for in vitro studies. The colour and appearance of TEO was pale yellow liquid (Sample No. TONE-00321). Essential oil was stored at $4^{\circ} \mathrm{C}$ away from direct light. For oral administration, TEO was dissolved in paraffin oil. Composition of TEO has been reported earlier (Liju et al., 2011).

\section{Chemicals}

Nicotinamide adenine dinucleotide phosphate reduced (NADPH), Agar agar, L- histidine, D-biotin, NADP, glucose-6-phosphate, dimethyl sulphoxide and sodium azide $\left(\mathrm{NaN}_{3}\right)$ were obtained from Sisco Research Laboratories, Mumbai, India. Nutrient broth was purchased from Hi-media laboratories, Mumbai. N-Methyl-N'-nitro-N-nitrosoguanidine (MNNG), 4-nitro-O-phenylenediamine (NPD), 2-acetamidoflourene (2-AAF), 7-ethoxy resorufin (ER), 7-pentoxy resorufin (PR), 7-methoxy resorufin (MR) and 7, 12-dimethylbenz (a) anthracene (DMBA) were purchased from Sigma chemicals (St. Louis, MO, USA). Phenobarbitone (Gardenal $^{\mathrm{R}}$ 60, Batch No.B03007) was purchased from Nicholas-Piramel India Ltd, Gujarat, India. Dimethyl sulfoxide (DMSO) and liquid paraffin were purchased from Merck Specialties Private Ltd., Mumbai, India. Tobacco was purchased from local market. All other chemicals were of analytical grade. Croton oil was prepared from the seeds of Croton tiglium $L$. by light ether petroleum extraction. All other reagents were of analytical grade

\section{Animals}

Male Wistar rats (8-10 weeks aged) weighing 150 \pm 20 $\mathrm{g}$ and Balb/C mice weighing 20-25g were purchased from Small Animal Breading Station, Kerala Veterinary and Animal Sciences University, Mannuthy, Kerala, India. The animals were maintained under standardized environmental conditions $\left(22-28^{\circ} \mathrm{C}, 60-70 \%\right.$ relative humidity, $12 \mathrm{~h}$ dark/light cycle). They were housed in well ventilated cages and fed with pelleted diet (Sai Durga Agency, Bangalore, India) and water ad libitum. All the animal experiments were done as per the instructions prescribed by the Committee for the Purpose of Control and Supervision of Experiments on Animals (CPCSEA), Ministry of Environment and Forest, Government of India, and implemented through the Institutional Animal Ethical Committee of the Amala Cancer Research Centre.

\section{Evaluation of antimutagenicity of TEO}

Bacterial strains: auxotrophic Salmonella typhimurium strains TA 98, TA 100 and TA 1535 were purchased from Gene Bank \& MTCC, Chandigrah, India. TA 102 mutant strain was kindly provided by Dr. Padma Ambalam,
Sourashtra University, Gujarat, India. For antimutagenicity study $S$. typhimurium strains were prepared from frozen permanent by inoculating the strains in nutrient broth $(5 \mathrm{ml})$ and incubating for $12 \mathrm{~h}$ at $37^{\circ} \mathrm{C}$. Genotype of the $S$. typhimurium strains TA 98, TA 100 and TA 1535 were checked using crystal violet sensitivity, histidine requirement, ampicillin and tetracycline resistance. TA 102 strain was checked by UV-sensitivity (Maron and Ames, 1983).

Mutagens: the mutagens, N-Methyl-N'-nitro$\mathrm{N}$-nitrosoguanidine (MNNG) ( $1 \mu \mathrm{g} / \mathrm{plate})$, 2-acetamidoflourene (2-AAF) $(20 \mu \mathrm{g} /$ plate), sodium azide $\left(\mathrm{NaN}_{3}\right)(2.5 \mu \mathrm{g} /$ plate $)$ were dissolved in water and 4-NitroO-phenylenediamine (NPD) $(20 \mu \mathrm{g} /$ plate $)$ was dissolved in dimethyl-sulfoxide (DMSO). For antimutagenicity studies tobacco extract was prepared by cutting $100 \mathrm{~g}$ of tobacco into small pieces and boiling in $500 \mathrm{ml}$ of distilled water. This was evaporated to dryness and $50 \mathrm{mg}$ of the extract was incorporated into each plate, which can produce mutagenic response.

\section{Evaluation of antimutagenic potential of TEO}

Antimutagenicity of TEO was tested against mutagens such as sodium azide, NPD and MNNG using TA 100, TA 1535, TA 98 and TA 102 strains Salmonella typhimurium by the method of Maron and Ames, (1983) and modified by Kaur et al. (1998) in triplicate. Concentrations of TEO used for evaluating the antimutagenicity were $0.1,0.5$ and $1 \mathrm{mg} / \mathrm{plate}$. TEO was added to $2 \mathrm{ml}$ of top agar at $45^{\circ} \mathrm{C}$ $(0.5 \% \mathrm{NaCl}$ and $0.6 \%$ agar) containing $0.5 \mathrm{mM}$ histidinebiotin, bacterial culture of $1-2 \times 10^{9}$ cells $/ \mathrm{ml}(0.1 \mathrm{ml})$ and direct acting mutagens at concentrations mentioned above. It was mixed well and poured into minimal agar plates. After incubation at $37^{\circ} \mathrm{C}$, the number of histidine independent revertant colonies were counted using colony counter. The plates with mutagen alone acted as positive control and plates without test sample and mutagen were considered as negative controls or spontaneous revertants.

In the case of mutagen needing activation, 2-acetamidoflourene (2-AAF) (20 $\mu \mathrm{g} /$ plate), Salmonella strains TA 98 or TA 100 , different concentrations of TEO, $0.1 \mathrm{ml}$ bacteria $\left(1-2 \times 10^{9}\right.$ cells $\left./ \mathrm{ml}\right), 0.5 \mathrm{ml} \mathrm{S} 9 \mathrm{mix}$ containing $0.2 \mathrm{M}$ sodium phosphate buffer ( $\mathrm{pH}$ 7.4), NADP $(0.1 \mathrm{M}), 1 \mathrm{M}$ glucose 6 phosphate, $10 \mu \mathrm{IgCl}_{2}-$ $\mathrm{KCl}$ and 2-AAF were incubated for $45 \mathrm{~min}$ at $37^{\circ} \mathrm{C}$. This mixture was then added to $2 \mathrm{ml}$ of melted top agar, gently mixed and overlaid onto the minimal glucose agar plates. After solidification, the plates were inverted and incubated for $48 \mathrm{~h}$ at $37^{\circ} \mathrm{C}$. The number of revertant colonies were counted using colony counter. All the plates were prepared in triplicate. The percentage inhibition of mutagenicity was calculated using the formula: Percentage inhibition $=[(C-S R) \times(T-S R) \div(C-S R)] \times 100$, where $\mathrm{C}$ is the number of revertants in the presence of mutagen alone, $\mathrm{T}$ is the number of revertants in the presence of TEO with mutagens and SR is the spontaneous revertants. No antimutagenic effect was considered if the percentage of inhibition was smaller than $25 \%$, a moderate effect if value is between $25 \%$ and $40 \%$ and a strong antimutagenic activity if value is greater than $40 \%$. Untreated plates (without mutagens) and plates treated 
with DMSO (Vehicle control) were also kept. The plates with diagnostic mutagen acted as positive control and plates without test sample and mutagen were considered as negative controls or spontaneous revertants.

Determination of the effect of TEO on DMBA and croton oil induced papilloma formation in mice

Male Balb/c mice were used for the DMBA induced skin papilloma study. DMBA, croton oil and TEO was applied on the shaved dorsal side ( $2 \mathrm{~cm}$ diameter) of the mice at least two days before the application of chemicals. Animals having no hair growth after 2 days were selected for the experiment. Balb/C mice were divided in to eight groups and each group having 8 animals.

Single dose of DMBA (470 nmol/mouse dissolved in $200 \mu 1$ acetone) was used for the study. All groups were applied with $1 \%$ croton oil in acetone (200 $\mu \mathrm{l} /$ animal) twice weekly for six weeks except group VI and VIII. TEO dissolved in paraffin oil was applied twice weekly for 6 weeks 30 minutes before each croton oil application. The animals in all groups were watched for food intake as well as any apparent toxicity such as weight loss or mortality during the entire period of the study. Skin papilloma formation was recorded weekly and the tumor growth greater than $1 \mathrm{~mm}$ in diameter was included in the cumulative total if they persisted for 2 weeks or more. Formation of the onset papilloma and number of papilloma per cage in various groups were recorded every week.

Effect of TEO on the inhibition of various isoforms of cytochrome $p 450$ enzymes

Rats were administered with phenobarbitone continuously for 4 days ( $60 \mathrm{mg} / \mathrm{kg}$ body weight, once daily) and sacrificed $24 \mathrm{~h}$ after the last dose of phenobarbitone. The livers of all the rats were excised quickly, washed thoroughly in ice-cold saline and kept at $-70^{\circ} \mathrm{C}$. Liver homogenate $(25 \%)$ was made in cold phosphate buffer ( $\mathrm{pH} 7.4,0.1 \mathrm{M})$. Homogenate was initially centrifuged at $14000 \mathrm{~g}$ for $20 \mathrm{~min}$ in a cold centrifuge (Remi) and supernatant was then further centrifuged at $10,5000 \mathrm{~g}$ for $1 \mathrm{~h}$ in an ultracentrifuge (Sorvall). The microsomes obtained from liver homogenate were washed and resuspended in cold phosphate buffer $(\mathrm{pH} 7.4,0.1 \mathrm{M})$ and used for determination of the effect of TEO on the dealkylation of methoxy resorufin by 7-methoxyresorufinO-demethylase (MROD), CYPIA2, pentoxy resorufin by 7-pentoxyresorufin-O-depentylase (PROD), CYP2B1/2 and ethoxy resorufin by 7-ethoxyresorufin-O-deethylase (EROD), CYP1A1 (Pohl and Fouts, 1980; Nerurkar et al., 1993).

Reaction mixture containing sodium phosphate buffer (0.1 M, pH 7.4), $6.25 \mathrm{mM} \mathrm{MgSO}{ }_{4}, 60 \mu \mathrm{M}$ EDTA, $5 \mu \mathrm{M}$ (ER, MR or PR), $100 \mu \mathrm{g}$ microsomal protein, and various concentrations of essential oil (50-200 $\mu \mathrm{g}$ ) in a final volume of $1 \mathrm{ml}$ was incubated for $5 \mathrm{~min}$ at $37^{\circ} \mathrm{C}$. The reaction was stopped by the addition of 2 $\mathrm{ml}$ of chilled methanol. The precipitated protein was centrifuged and supernatant was used for the estimation of enzyme activity by measuring resorufin formed using a fluorescent spectrophotometer (Nanodrop ND-3300, Thermo Scientific, USA.) at the excitation wavelength of $550 \mathrm{~nm}$ and the emission wavelength of $585 \mathrm{~nm}$. Blanks were set without addition of NADPH. The percentage inhibition was calculated by the following formula: $\mathrm{C}-\mathrm{T} /$ $\mathrm{C} \times 100$. Where $\mathrm{C}$ is the optical density of control without essential oil, $\mathrm{T}$ is the optical density with essential oil.

Aminopyrene-N-demethylase activity (an indicator of CYP 1A, 2A, 2B, 2D and 3A activity) was measured at various concentration of TEO $(50,100$ and $200 \mu \mathrm{g})$ by the method of Mazel, (1971). Aminopyrene was dealkylated by microsomal enzymes to form 4-amino antipyrene and formaldehyde. Formaldehyde so formed was measured by condensation with Nash reagent. The colour development and absorbance was measured at $412 \mathrm{~nm}$. The percentage of inhibition was calculated.

\section{Statistical analysis}

The values are expressed as mean $\pm \mathrm{SD}$. The statistical significance was compared between control and tested groups by one way analysis of variance (ANOVA) followed by appropriate post hoc test (Dunnet multiple comparison test) using Graph pad in Stat software.

\section{Results}

\section{Evaluation of antimutagenic potential of TEO}

Earlier studies indicated that TEO did not show any mutagenicity and cytotoxicity up to a concentration of 3 $\mathrm{mg} /$ plate (Liju et al., 2013) against $S$. typhimurium strains.

Table 1. Groups, Treatment and Number of Animals

\begin{tabular}{llc}
\hline Groups & Treatment & No. of animals \\
\hline SI & DMBA+croton oil & 8 \\
II & DMBA+croton oil+Paraffin oil & 8 \\
III & DMBA+croton oil+10\% TEO & 8 \\
IV & DMBA+croton oil+25\% TEO & 8 \\
V & DMBA+croton oil+50\% TEO & 8 \\
VI & DMBA alone & 6 \\
VII & Croton oil alone & 6 \\
VIII & DMBA+TEO & 8 \\
\hline
\end{tabular}

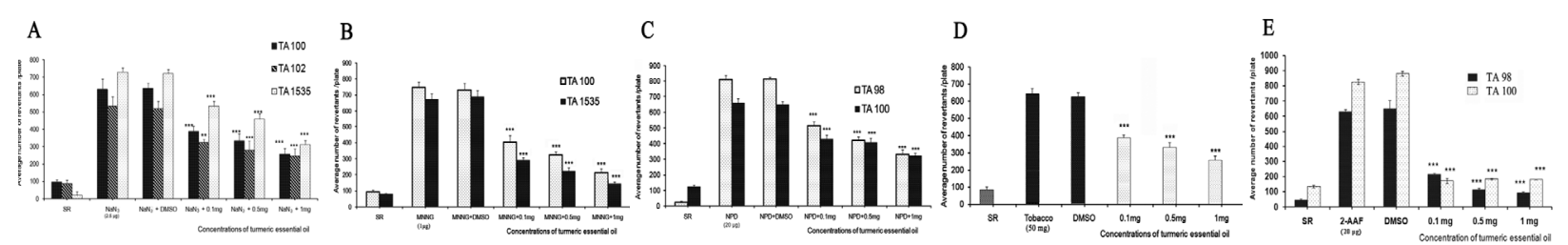

Figure 1. Antimutagenic Activity of Turmeric Essential Oil on Mutagenicity Induced by $\mathrm{NaN}_{3}, \mathrm{MNNG}$, NPD, Tobacco and 2-AAF in Salmonella Strains. (A) $\mathrm{NaN}_{3}$, Sodium azide. DMSO, dimethyl-sulfoxide (Vehicle control); (B) MNNG, N-Methyl-N'-nitro-N-nitrosoguanidine; (C) NPD, 4-Nitro-O-phenylenediamine; (D) tobacco; (E) 2-AAF, 2-acetamidoflourene; Data shown are mean values with bars indicating the standard deviation of the mean $(n=3)$. $* * * \mathrm{p}<0.001, * * \mathrm{p}<0.01$ when compared with positive control 


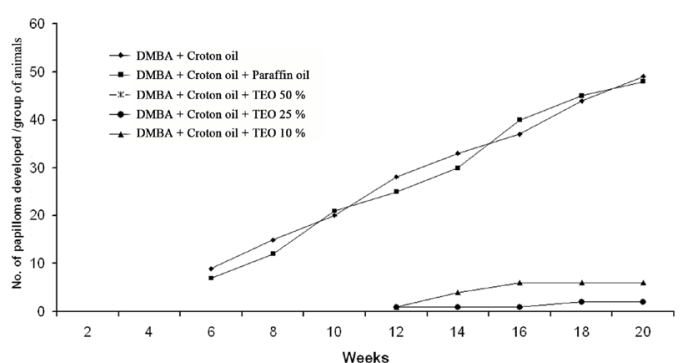

Figure 2. Chemopreventive Effect of Turmeric Essential Oil (TEO) on the Onset of Skin Papilloma Formation after Topical Application of 7, 12-dimethylbenz (a) Anthracene (DMBA) (470 nmol/mouse, dissolved in $200 \mu \mathrm{l}$ acetone) and $1 \%$ Croton Oil in mice

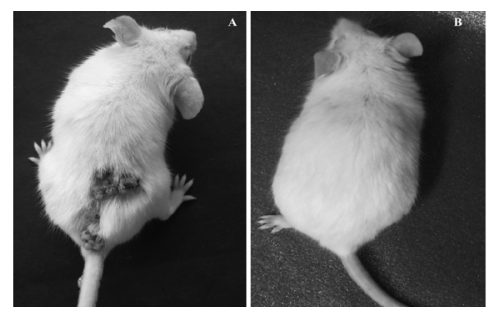

Figure 3. Effect of Turmeric Essential Oil (TEO) on Skin Papilloma Induction Initiated by Topical Application of 7, 12-dimethylbenz (a) Anthracene (DMBA) (470 nmol/mouse, dissolved in $200 \mu \mathrm{l}$ acetone) and Promoted by $1 \%$ Croton Oil in mice. (A) DMBA and croton oil treated mice with skin papilloma. (B) DMBA + Croton oil $+50 \%$ TEO treated mice with no papilloma

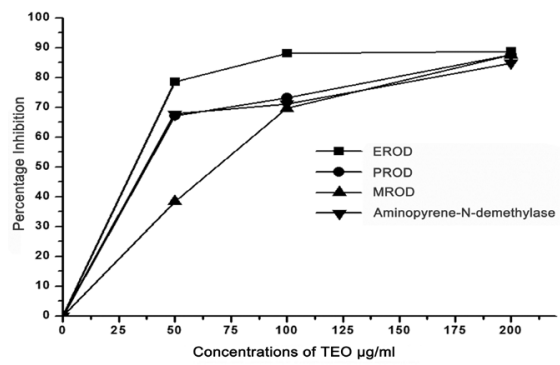

Figure 4. Effect of Turmeric Essential Oil (TEO) on Inhibition of Cytochrome p450 Enzymes in vitro

Table 2. Inhibition of Cytochrome p450 Enzymes by TEO (in vitro)

\begin{tabular}{|c|c|c|}
\hline Cytochrome p450 enzymes & \multicolumn{2}{|c|}{$\mathrm{IC}_{50}$ Values of TEO } \\
\hline CYP1A2 (MROD) & & $66 \mu \mathrm{g}$ \\
\hline CYP2B 1/2 (PROD) & & $36 \mu \mathrm{g}$ \\
\hline CYP1A1 (EROD) & & $31 \mu \mathrm{g}$ \\
\hline CYP 1A, 2A, 2B, 2D and 3A & (Aminopyrene-N-demethylase) & $45 \mu \mathrm{g}$ \\
\hline
\end{tabular}

*MROD, 7-methoxyresorufin-O-demethylase; PROD, pentoxy resorufin by 7- pentoxyresorufin O-depentylase; EROD, ethoxy resorufin by 7-ethoxyresorufin O-deethylase

We selected three different concentrations of TEO - 0.1, 0.5 and $1 \mathrm{mg} /$ plate for evaluating antimutagenicity. All the strains of $S$. typhimurium (TA 98, TA 100, TA 102 and TA 1535) produced several fold revertant colonies compared to spontaneous revertant after treatment with mutagens. TEO showed significant antimutagenic activity against mutagens such as $\mathrm{NaN}_{3}$, MNNG, NPD, 2-AAF and tobacco on all the 4 Salmonella strains studied with or without activations in a concentration dependent manner. DMSO alone (vehicle control) did not produce any antimutagenic activity.
TEO inhibited $\mathrm{NaN}_{3}$-induced mutagenicity by $70.3 \%$ (TA100), 65.8\% (TA102) and 59.2\% (TA 1535) at a concentration of $1 \mathrm{mg} /$ plate, (Figure 1A). MNNG induced mutagenicity was inhibited by $81.6 \%$ (TA100) and $89.1 \%$ (TA1535) (Figure 1B) and NPD-induced mutagenicity by $62.6 \%$ (TA98) and $63.1 \%$ (TA100) by TEO at a concentration of $1 \mathrm{mg} /$ plate (Figure 1C). TEO also significantly exhibited antimutagenicity (81.7\%) against tobacco extract in Salmonella strain TA 102 at the concentration of $1 \mathrm{mg} /$ plate (Figure 1D).

TEO exhibited strong $(\mathrm{P}<0.001)$ antimutagenic activity against 2-AAF after metabolic activation. TEO inhibited mutagenicity by $92.6 \%$ and $94.5 \%$ at the concentration of $1 \mathrm{mg}$ / plate in Salmonella TA 98 and TA 100 strains respectively. The percentage inhibition of antimutagenic activity of TEO against 2AAF is shown in Figure 1E.

Determination of the effect of TEO on DMBA and croton oil induced papilloma development in mice

Papilloma development in mice was started 6th week in control and vehicle control group. Onset of papilloma was found to be significantly delayed or prevented by TEO treatment. In TEO (10 and 25\%) treated groups, formation of papillomas were started in the $12^{\text {th }}$ week after DMBA application. DMBA alone, croton oil alone and DMBA+croton oil+50\% TEO treated groups did not produce any papilloma on mice. At the end of $20^{\text {th }}$ week the average number of papilloma per mouse was $7 \pm 1.06$ and $6.86 \pm 1.04$ in control and vehicle control group respectively and this number was reduced to $1.2 \pm 0.5$ and $1 \pm 0.3$ by topical application of TEO $10 \%$ and $25 \%$ respectively (Figure 2). Inhibition of development of papilloma was $82.9,85.7$ and $100 \%$ in 10,25 and $50 \%$ TEO treated groups respectively (Figure 3 ).

Effect of TEO on the inhibition of various isoforms of cytochrome $p 450$ enzymes

Administration of phenobarbitone increased the level of cytochrome p450 enzymes EROD, MROD and PROD in rats, when compared with untreated group. Oral gavage of TEO significantly inhibited EROD activity. Percentage inhibition of EROD at various concentration of TEO such as 50,100 and $200 \mu \mathrm{g} / \mathrm{ml}$ was $78.7 \%, 80.6 \%$ and $83.8 \%$ respectively (Figure 4 ). TEO significantly inhibited MROD activity $(\mathrm{P}<0.001)$ and $80 \%$ inhibition was shown at $200 \mu \mathrm{g} / \mathrm{ml}$. Similarly activity of PROD was also inhibited by TEO at various concentrations which were $63.5 \%, 66.4 \%$ and $81.1 \%$. Aminopyrene-N-demethylase activity is an indicator of CYP 1A, 2A, 2B, 2D and $3 \mathrm{~A}$. TEO inhibited the activity of aminopyrene-N-demethylase significantly $(\mathrm{P}<0.001)$ at various concentration $(50,100$ and $200 \mu \mathrm{g} / \mathrm{ml}$ ) (Figure 4). IC I0 values of MROD, PROD, EROD and aminopyrene-N-demethylase by TEO is given in Table 2.

\section{Discussion}

Cancer is one of the major health problems in the present world. The main reason for the cause of cancer is genetic mutation especially influenced by industrial and environmental pollutants. Mutagenicity indicates 
perpetual transmissible changes in the structure of genetic material in the cells of living organisms. Prolonged exposure to chemical mutagens present in agricultural, food, medicine and industry causes DNA mutations that can lead to carcinogenesis. Mutagenic potential of substances can be detected through Ames assay which is a very fast and economical test (Ames et al., 1975). It is assessed that $90 \%$ of the mutagens are carcinogens. Secondary metabolites from medicinal plants and spices have significant role in preventing cancer by acting as chemopreventive agents. Chemopreventive agents can be targeted for intervention at any of stage of carcinogenesis stage i.e., initiation, promotion or progression (Sulaiman et al., 2012).

Curcuma longa is a well known traditional spice with more than 1700 research articles published about this spice. TEO isolated from rhizome of Curcuma longa by steam distillation, has significant pharmacological and medicinal properties (Funk et al., 2010). In the present study, we have evaluated the antimutagenic and anticarcinogenic potential of TEO. We have also studied the effect of TEO in the regulation of cytochrome $\mathrm{p} 450$ enzymes in vitro.

$\mathrm{NaN}_{3}$ is a potent mutagen in plants, bacterial species and a mammalian cell as well as it has high specificity in Salmonella and E. coli species. MNNG can produce DNA adduct formation and may cause gastrointestinal tract related cancer (Matsuyama et al., 1970; Lucchesi et al., 1986). It is present in detergent, cosmetic items and cigarettes smoke etc. NPD is mutagen present in cosmetics and induced frame shift mutation in Salmonella typhimurium (TA98 and TA100). Tobacco contains different compounds; most of them are identified as cancer causing. Moreover 2-Acetylaminofluorene (2-AAF) is a potent arylamine carcinogen and activation is done by cytochrome p450 enzymes. Antimutagenic studies using different auxotrophic Salmonella strains indicated that the TEO significantly inhibited the mutagenicity produced by all the direct acting mutagens, sodium azide, NPD, MNNG and tobacco and also inhibited the activation of 2-AAF by rat liver $\mathrm{S} 9$ fraction in a dose dependent manner. The antimutagenic property of essential oil may be due to inactivation of mutagens by inhibition of free radicals or activation of cellular antioxidant enzymes, inhibition of cytochrome $\mathrm{p} 450$ enzymes or activation of detoxification of mutagens (Shankel et al., 1993; Water et al., 1996; Ipek et al., 2005). TEO is also known to possess significant in vivo and in vitro antioxidant activity (Liju et al., 2011). Significant antimutagenic activity of TEO may be linked to anticarcinogenic potential.

The pro-carcinogens are known to under go bioactivation by cytochrome p450 enzymes and converted to active carcinogens. Cytochrome p450 is a superfamily most of which are present in liver and plays an important role in the metabolism of drugs as well as endogenous and exogenous chemicals. Well-known pro-carcinogenic compounds such as aflatoxin, 3-methylcholanthrene (3$\mathrm{MC}), 2-\mathrm{AAF}, \mathrm{DMBA}$ are metabolized by the action of isoforms of cytochrome p450 enzymes and converted into potent carcinogenic compounds. Activation of promutagen 2-AAF is done by the presence of enzymes
CYP1A2 in liver (Firdous et al., 2010; Yueh et al., 2001). CYP1A2 is the most efficient cytochrome $\mathrm{p} 450$ enzyme catalysing the $\mathrm{N}$-hydroxylation of the dietary heterocyclic amines. Moreover Cytochrome p450 enzymes such as CYP1A1 and 1B1 usually metabolize polycyclic aromatic hydrocarbons (3-MC) into carcinogen (Thorgeirsson and Nebert, 1977). Present study revealed that level of cytochrome p450 enzymes such as CYP1A2, CYP2B 1/2, CYP1A1, CYP2A, CYP2D and CYP3A are significantly reduced after treated with TEO in a concentration dependent manner. Reactive oxygen species plays an important role as initiators as well as promoters of mutagenesis and carcinogenesis and our previous study indicated that TEO significantly scavenge reactive oxygen species in vitro and in vivo (Arya and Kumar, 2011; Liju et al., 2011). Antioxidants are generally acted as antimutagenic and anticarcinogenic agents due to their free radical scavenging properties (Ames et al., 1993; Clark, 2002).

DMBA is a polycyclic aromatic hydrocarbon and mostly used for studies in carcinogenic animal model experiment (Hamizah et al., 2012). DMBA is metabolized by CYP1A1 and CYP1B1, which convert DMBA to the ultimate carcinogen 1, 2-epoxide-3, 4-diol DMBA (Anqus et al., 1999; Buters et al., 1999; Kawajiri and Ikuta, 1999; Sharma et al., 2012), which form adducts with DNA and it leads to carcinogenesis (Cheng et al., 1988). Suppression of CYP1A1 enzyme activity by TEO can reduce the effect of DMBA induced carcinogenesis. In present study we have showed that the incidence and number of skin papillomas formation after treated with 7 , 12 dimethylbenz[a] anthracene and promoted by croton oil was significantly decreased (10 and $25 \%$ TEO; $p<0.001$ ) and absolutely prevented ( $50 \%$ TEO treated group) by treatment with TEO in mice. This implies that TEO may have either inhibited the metabolism of DMBA to its active form, or delayed the promotion phase of carcinogenesis (Agrawal and Sonam, 2009).

Detoxification and elimination of DMBA are done by phase II enzymes such as glutathione-s-transferase (GST) and UDP-glucuronyl transferase. Previous study showed that TEO administration enhanced phase II enzymes. Inhibition of cytochrome p450 enzymes and promotion of phase II enzymes in liver would inhibit the metabolic activation of DMBA and prevent cancer formation. These results suggest the role of TEO as chemopreventive and anticancer agent. It is already reported that TEO did not show any toxicity and genotoxicity in rats up to concentration of $500 \mathrm{mg} / \mathrm{kg}$ body weight (Liju et al., 2013). FDA has accepted that TEO can be used as food additive and is recommended as GRAS.

Previous study indicated that TEO did not produce any mutagenicity to Salmonella strains with and without activation of S9 mixture (Liju et al., 2013). In this study we have shown TEO has strong antimutagenic potential against know chemical mutagens such as $\mathrm{NaN}_{3}$, MNNG, NPD and tobacco as well as 2-AAF which needs metabolic activation. Moreover TEO significantly delayed and prevented the skin papilloma development in DMBA and croton oil treated mice. Antimutagenicity and anticarcinogenic activity of TEO may be due to its 
antioxidant activity as well as suppression of mutagen inducing metabolizing cytochrome p450 enzymes such as CYP1A1, CYP1A2, CYP2B, CYP2A, CYP2D and CYP3A.

\section{Acknowledgements}

Authors are thankful to Spice Board of India, for providing financial assistance to carry out this work. The author (s) declared no conflicts of interest with respect to the authorship and / or publication of the article.

\section{References}

Agrawal RC, Sonam P (2009). Evaluation of anticarcinogenic and antimutagenic potential of Bauhinia variegata extract in Swiss albino mice. Asian Pac J Cancer Prev, 10, 913-6.

Ames BN (1983). Dietary carcinogens and anticarcinogens. Oxygen radicals and degenerative diseases. Science, 221, 1256-64.

Ames BN, Mccann J, Yamasaki E (1975). Methods for detecting carcinogens and mutagens with the Salmonella/mammalianmicrosome mutagenicity test. Mutat Res, 31, 347-64.

Ames BN, Shigenaga MK, Hagen TM (1993). Oxidants, antioxidants, and the degenerative diseases of aging. Proc Natl Acad Sci USA, 90, 7915-22.

Anqus WG, Larsen MC, Jefcoate CR (1999). Expression of CYP1A1 and CYP 1B1 depends on cell-specific factors in human breast cancer cell lines: role of estrogen receptor status. Carcinogenesis, 20, 947-55.

Arya P, Kumar M (2011). Chemoprevention by Triticum aestivativum of mucus skin carcinogenesis induced by DMBA and croton oil association with oxidative status. Asian Pac J Cancer Prev, 12, 143-8.

Baik KU, Jung SH, Ahn BZ (1993). Recognition of pharmacophore of ar-turmerone for its anticancer activity. Arch Pharmacal Res, 16, 254-6.

Buters JT, Sakai S, Richter T, et al (1999). Cytchrome p450 CYP1B1 determines susceptibility to 7,12-dimethylbenz[a] anthracene lymphomas. Proc Natl Acad Sci USA, 96, 197782.

Cheng SC, Prakash AS, Pigott MA, et al (1988). Characterization of 7,12-dimethylbenz(a)anthracene- adenine nucleoside adducts. Chem Res Toxicol, 1, 216-21.

Clark SF (2002). The biochemistry of antioxidants revisited. Nutr Clin Pract, 17, 5-17.

Deepa DA, Anita B, Sreelatha KT (2010). Comparative study of the efficacy of curcumin and turmeric oil as chemopreventive agents in oral submucous fibrosis: a clinical and histopathological evaluation. JIAOMR, 22, 88-92.

Firdous AP, Sindhu ER, Ramnath V, Kuttan R (2010). Antimutagenic and anticarcinogenic potential of the carotenoid meso-zeaxanthin. Asian Pac J Cancer Prev, 11, 1795-800.

Funk JL, Frye JB, Oyarzo JN, Zhang H, Timmermann BN (2010). Anti-Arthritic effects and toxicity of the essential oils of turmeric (Curcuma longa L). J Agric Food Chem, $\mathbf{5 8}, 842-9$.

Hamizah S, Roslida AH, Fezah O, Tank L (2012). Chemopreventive potential of Annona murieata L leaves on chemically induced skin papillomagenesis in mice. Asian Pac J Cancer Prev, 13, 2533-9.

Hastak K, Lubri N, Jakhi SD, et al (1997). Effect of turmeric oil and turmeric oleoresin on cytogenetic damage in patients suffering from oral submucous fibrosis. Cancer Lett, 116, 265-9.

6580 Asian Pacific Journal of Cancer Prevention, Vol 15, 2014
Ipek E, Zeytinoglu H, Okay S, et al (2005). Genotoxicity and antigenotoxicity of origanum oil and carvacrol evaluated by Ames Salmonella/microsomal test. Food Chem, 93, 551-6.

Kaur S, Grover IS, Singh M, Kaur S (1998). Antimutagenicity of hydrolyzable tannins from Terminalia chebula in Salmonella typhimurium. Mutat Res, 419, 169-79.

Kawajiri K, Ikuta T (1999). Regulatory mechanism of phase I drug-metabolizing enzymes. Tanqakushitsu Kakusan Koso, 44, 2377-83.

Liju VB, Jeena K, Kuttan R (2011). An evaluation of antioxidant, anti-inflammatory and antinociceptive activities of essential oils from curcuma longa. Indian J Pharmacol, 43, 526-31.

Liju VB, Jeean K, Kuttan R (2013). Acute and subchronic toxicity as well as mutagenic evaluation of essential oil from turmeric (Curcuma longa L). Food Chem Toxicol, 53, 52-61.

Lucchesi P, Carraway M, Marinus MG (1986). Analysis of forward mutations induced by N-methyl-N-nitro-Nnitrosoguanidine in the bacteriophage P22 mnt repressor gene. J Bacteriol, 166, 34-7.

Manosroi J, Dhumtanom P, Manosroi A (2006). Anti-proliferative activity of essential oil extracted from Thai medicinal plants on KB and P388 cell lines. Cancer Lett, 235, 114-20.

Maron DM, Ames BN (1983). Revised methods for Salmonella mutagenicity test. Mut Res, 113, 173-215.

Matsuyama M, Suzuki H, Nakamura T (1970). Leiomyosarcomas induced by oral administration of N-methyl-Nnitrosoguanidine in gastric cyst grafted in subcutaneous tissue of mice. Gann, 61, 523-7.

Mazel P (1971). Experiments illustrating drug metabolism in vitro. In 'Fundamentals of Drug Metabolism and Drug Disposition', Eds La Du BN, Mandel H, Way EL. Williams \& Wilkins, Baltimore pp 546-52.

Negi PS, Jayaprakasha GK, Jagan Mohan RL, Sakariah KK (1999). Antibacterial activity of turmeric oil: a byproduct from curcumin manufacture. J Agric Food Chem, 47, 4297-300.

Nerurkar PV, Park SS, Thomas PE, Nims RW, Lubet RA (1993). Methoxyresorufin and benzyloxy resorufin: substrates preferentially metabolized by cytochromes p450 1A2 and $2 \mathrm{~B}$ respectively in the rat and mouse. Biochem Pharmacol, 46, 933-43.

Piengchai K, Anong T, Nopsaran T, et al (2011). Anticlastogenic and anticarcinogenic potential of thai bitter gourd fruits. Asian Pac J Cancer Prev, 12, 1299-05.

Pohl RJ, Fouts JR (1980). A rapid method for assaying the metabolism of 7-ethoxyresorufin by microsomal subcellular fractions. Anal Biochem, 107, 150-5.

Shankel DM, Huo S, Haines C, Mitscher LA(1993). Extracellular interception of mutagens. Basic Life Sci, 61, 65-74.

Sharma V, Paliwal R, Janmeda P, Sharma S (2012). Chemopreventive efficacy of Moringa oleifera pods against 7, 12-dimethylbenz[a]anthracene induced hepatic carcinogenesis in mice. Asian Pac J Cancer Prev, 13, 2563-9.

Sulaiman H, Roslida AH, Fezah O, et al (2012). Chemopreventive potential of Annona muricata 1 leaves on chemically-induced skin papillomagenesis in mice. Asian Pac J Cancer Prev, 13, 2533-9.

Thorgeirsson SS, Nebert DW (1977). The Ah locus and the metabolism of chemical carcinogens and other foreign compounds. Adv Cancer Res, 25, 149-93.

Water MD, Stack HF, Jackson MA, Brockman HE, De Flora S (1996). Activity profiles of antimutagens: in vitro and in vivo data. Mutat Res, 350, 109-29.

Yueh MF, Nguyen N, Famourzadeh M, et al (2001). The contribution of UDP-gluccuronosyltransferase 1 A9 on CYP1A2-mediated genotoxicity by aromatic and heterocyclic amines. Carcinogenesis, 22, 943-50. 